\title{
Sciendo
}

Administration, vol. 68, no. 1 (2020), pp. 15-26

doi: 10.2478/admin-2020-0002

\section{Civil service, 2019}

\author{
Laura Shannon \\ Institute of Public Administration, Ireland
}

The Irish civil service performs well in many international comparative statistical indicators. Ireland scores above average in terms of the quality of public administration and on civil service effectiveness, and leads the way with regard to open-data maturity. Furthermore, 62 per cent of the population tend to trust the public administration. On the other hand, Ireland continues to be the most centralised state in the OECD, with over 90 per cent of expenditure undertaken by central government. And while numbers employed in the civil service continue to rise, public service employment represents a much lower percentage of the overall labour force (at 15 per cent in 2015) than in many other OECD countries (Boyle, 2019).

\section{Recruitment}

The level of recruitment to the civil service continues to rise, with 42,540 employed at the end of September 2019. The Public Appointments Service (PAS) noted in its most recent annual report that 'demand for generalist grades is expected to remain close to the high levels attained during the course of 2018 into the medium term' (Public Appointments Service, 2019, p. 8). In 2018 there was a 6 per cent increase in the number of advertised campaigns and a 17 per cent increase in the number of applicants (totalling 88,881). The PAS also notes that demand is expected to continue to rise for specialist expertise in topical areas (e.g. climate change, cyber security) and areas such as risk, governance and compliance, project management, and media and communications. 


\section{Top-level recruitment}

In terms of top-level recruitment (assistant secretary level and above), a number of trends and shifts were noted in the most recent annual report of the Top Level Appointments Committee (TLAC). The number of vacancies was closer to the average range after a particularly busy 2017 . There were twenty-seven vacancies at the top level of the civil service in 2018, twenty general service and seven specialist roles. Appointments were made in all but two competitions, both specialist posts.

The positive shift towards gender diversity was noted, with more women than men appointed to the top two grades in the civil service for the first time. Of the twenty-five recommendations made by the TLAC, sixteen were women (64 per cent). In the TLAC's view, this shift is 'evidence of the Government and senior civil service leaders' support for greater gender balance in top leadership roles' and this level of support 'is likely to deliver further improvements in 2019' (Top Level Appointments Committee, 2019, p. 4).

New analysis undertaken by the TLAC has shown that specialist roles are distinct from general service, attracting applications from a different blend of sources, and having a different gender balance and success rate in filling positions. The gender balance is particularly noticeable, with all five specialist appointments in 2018 going to women candidates. There is also much more diversity in terms of appointments from outside the civil service for specialist posts, with just 33 per cent of applications coming from civil servants (compared to 58 per cent of applications for generalist posts). Civil servants do, however, succeed at higher rates than they do for general service roles.

The TLAC also expressed concern at the falling levels of applications per competitions, noting that 'attraction and retention of talent has become a very competitive game'. In 2018 there was an average of twenty-three applicants per competition, which is significantly lower than the average of twenty-nine over the previous seven years.

\section{Public Service Pay Commission}

The Public Service Pay Commission (PSPC) was established in 2016 to advise the government on public service remuneration policy. Module 2 of its work focused on recruitment and retention issues in the Permanent Defence Forces and other grades where particular 
difficulties had been identified in its first report. In May a report was published addressing issues relating to the Permanent Defence Forces. Its fourth and final report was published in July 2019, covering issues relating to senior executive public servants, specialist grades and certain public health professionals (Public Service Pay Commission, 2019). The main findings of this report relative to the civil service in particular are summarised below.

\section{Specialist grades in the public service}

There would appear to be particular recruitment and/or retention challenges in certain niche areas, which may require exceptional intervention. Difficulties may also arise at an organisational level and these can be examined on a case-by-case basis. In the past, various devices (such as entry above minimum point on a scale, accelerated incremental progression, and allowances) were used to address specific recruitment challenges in specialist positions. These could provide a tailored, rather than a 'one size fits all', solution.

\section{Senior executive grades in the civil and public service}

The current policy for pay determination for senior posts continues to be affected by limits imposed at a time when economic conditions were substantially different to those that apply in the current labour market. As a result, pay for certain senior posts in the public service is under pressure, with decisions being taken on an ad hoc basis, which is undesirable.

The commission stated that it would consider it appropriate, should it be decided to conduct a review of remuneration of senior-level posts, that the Review Body on Higher Remuneration in the Public Sector be reconstituted for this purpose. The minister has instructed his officials to evaluate proposals in this regard.

\section{Public Service Stability Agreement (PSSA)}

The commission also noted that, while it was precluded from making recommendations on basic pay, submissions received throughout its work urged examination of this issue. In that regard, it recommended that the parties to the PSSA 'consider putting arrangements in place, at an appropriate time, and without compromising the stability of the public service pay bill, to allow for the adequacy of current pay arrangements more generally to be fully examined' (Public Service Pay Commission, 2019, p. 18). 


\section{Civil service renewal}

The Civil Service Renewal Plan (Government of Ireland, 2014), a major change management and reform programme specifically aimed at improving the civil service, was published in 2014. In May a fourth and final high-level progress report set out updates across all twenty-five actions and outlined significant transformations under four key themes and associated achievements, which are summarised below (Department of Public Expenditure and Reform, 2019a).

\section{Next phase for civil service renewal}

As mentioned, the previous Civil Service Renewal Plan delivered a range of transformations, aimed at increasing the capacity of the civil service to respond to complex challenges. Since 2014, and the launch of the plan, new challenges and opportunities have emerged at both local and global levels. Work is underway to develop a framework for the next stage of civil service reform and is being overseen by an interdepartmental taskforce of senior leadership from across the civil service. The strategy will comprise an overarching framework of values, principles and strategic priorities which will guide and inform the civil service and associated reform over the next number of years. The development of this plan will be informed by a focused consultation process with internal and external stakeholders, and it is expected to be published by Q3 2020.

\section{Summary of achievements from the Civil Service Renewal Plan 2014}

Outcome 1: A unified civil service - Managing the civil service as a single, unified organisation:

- establishing the Civil Service Management Board (CSMB); the CSMB, made up of secretaries general and heads of offices, has collective responsibility for civil service renewal;

- a common governance code has been adopted by every department;

- progress on shared services, including HR, payroll and pensions;

- pilot projects to test models for whole-of-government working;

- roll out of the Government of Ireland identity and Gov.ie as a shared online platform for all departments.

Outcome 2: A professional civil service - Maximising the performance and potential of all civil service employees and organisations: 
- development of a strategic HR agenda for 2017 to 2020 under the Civil Service People Strategy;

- open recruitment campaigns have been held and graduate development programmes have been established;

- establishment of OneLearning to deliver training across the civil service;

- executive leadership programmes at assistant secretary and principal officer level;

- a more simplified performance management system has been delivered.

Outcome 3: A responsive civil service - Changing our culture, structure and processes so that we become more agile, flexible and responsive:

- a new civil-service-wide mobility scheme has been introduced for clerical officers and executive officers, which will be extended to other grades up to assistant principal level in due course;

- a standardised project management approach has been introduced and supported with the establishment of a project managers' network and training from OneLearning;

- increased authority and accountability for managing staff resources has been introduced for organisations through delegated sanction arrangements;

- new workforce planning guidelines and templates have been developed, alongside training in this area for relevant managers;

- initiatives under the Public Service ICT Strategy included an eGovernment strategy, the launch of MyGovID.ie and the implementation of a common set of applications across a number of departments.

Outcome 4: An open and accountable civil service - Continuously learning and improving by being more open to external ideas, challenge and debate:

- open policy debates took place throughout the course of the plan, to involve networks of practitioners, academics and experts at the early stages of policy development;

- work is advancing on the development of guidance for policymaking to support departments on the fundamental stages of policymaking and ensure a consistent approach is embedded throughout the civil service; 
- a new system of organisational capability reviews to assess and strengthen performance and capacity across departments is being implemented;

- a new website, whodoeswhat.gov.ie, has been developed to publish the framework for assignment of responsibilities in line with the Public Service Management Act, 1997;

- guidelines and a handbook in relation to the transfer of functions have been published to assist in implementing government decisions to establish new departments or restructuring of existing departments;

- progress has been made to improve external communications; the secretary general of the Department of Public Expenditure and Reform (DPER) has been designated to act publicly as a spokesperson and ambassador for the civil service;

- under the Open Data initiative, progress is being made to improve how data is collected, managed and stored;

- progress on developing a National Data Infrastructure;

- two major civil service employee engagement surveys, the results of which are informing initiatives in departments across the civil service.

\section{Civil Service Excellence and Innovation Awards 2019}

The Civil Service Excellence and Innovation Awards were established under the Civil Service Renewal Plan to recognise the achievements of civil servants and showcase examples of best practice and innovation in government departments and offices. This year, ninety nominations were received and thirty-two projects were shortlisted; the eleven winning projects are included in Table 1 .

\section{Civil Service Customer Satisfaction Survey}

The eighth Civil Service Customer Satisfaction Survey, which began in 1997, was published in November. The survey measures satisfaction levels with services received from civil service departments and major offices. It was conducted by Ipsos MRBI on behalf of DPER. The fieldwork was carried out in Q2 2019 with 2,019 face-to-face interviews conducted nationwide. Some key findings are as follows:

- just under half of Irish adults have had an interaction with the civil service in the past year; interaction levels have increased for the 
Table 1: Civil Service Excellence and Innovation Awards, 2019

\begin{tabular}{|c|c|c|}
\hline Award & Department & Project \\
\hline $\begin{array}{l}\text { Excellence in Policy } \\
\text { Making and } \\
\text { Implementation }\end{array}$ & $\begin{array}{l}\text { Department of Foreign } \\
\text { Affairs and Trade }\end{array}$ & $\begin{array}{l}\text { Global Ireland: } \\
\text { Expansion of Ireland's } \\
\text { Diplomatic Network }\end{array}$ \\
\hline Excellence in Innovation & $\begin{array}{l}\text { Department of Business, } \\
\text { Enterprise and } \\
\text { Innovation }\end{array}$ & $\begin{array}{l}\text { DBEI Innovation } \\
\text { Week }\end{array}$ \\
\hline $\begin{array}{l}\text { Citizen Impact and } \\
\text { Customer Service }\end{array}$ & Department of Health & $\begin{array}{l}\text { Advanced Nursing } \\
\text { Practice }\end{array}$ \\
\hline Leading Reform & $\begin{array}{l}\text { Department of Public } \\
\text { Expenditure and Reform }\end{array}$ & $\begin{array}{l}\text { Single Scheme } \\
\text { Administration Project }\end{array}$ \\
\hline $\begin{array}{l}\text { Excellence in People, } \\
\text { Skill and Organisational } \\
\text { Development }\end{array}$ & Central Statistics Office & $\begin{array}{l}\text { SMART Start - Year } \\
\text { One Induction \& } \\
\text { Development } \\
\text { Programme }\end{array}$ \\
\hline $\begin{array}{l}\text { Excellence Through } \\
\text { Collaboration }\end{array}$ & $\begin{array}{l}\text { Department of Children } \\
\text { and Youth Affairs, and } \\
\text { Irish Youth Justice } \\
\text { Services }\end{array}$ & $\begin{array}{l}\text { Bail Supervision } \\
\text { Scheme }\end{array}$ \\
\hline $\begin{array}{l}\text { Research, Analytics } \\
\text { and Insight }\end{array}$ & $\begin{array}{l}\text { Department of } \\
\text { Communications, } \\
\text { Climate Action and } \\
\text { Environment/ } \\
\text { Department of Culture, } \\
\text { Heritage and the } \\
\text { Gaeltacht }\end{array}$ & $\begin{array}{l}\text { The ObSERVE } \\
\text { Programme }\end{array}$ \\
\hline $\begin{array}{l}\text { Integrated Digital } \\
\text { Excellence }\end{array}$ & $\begin{array}{l}\text { Department of } \\
\text { Employment Affairs } \\
\text { and Social Protection }\end{array}$ & $\begin{array}{l}\text { Treatment Benefit } \\
\text { goes Digital }\end{array}$ \\
\hline $\begin{array}{l}\text { Excellence in Culture, } \\
\text { Values and Diversity }\end{array}$ & $\begin{array}{l}\text { Department of Culture, } \\
\text { Heritage and the } \\
\text { Gaeltacht }\end{array}$ & $\begin{array}{l}\text { Fresh Approaches to } \\
\text { Driving Women's } \\
\text { Participation in the } \\
\text { Arts and Culture } \\
\text { Sector }\end{array}$ \\
\hline Employee Engagement & $\begin{array}{l}\text { Department of } \\
\text { Education and Skills }\end{array}$ & $\begin{array}{l}\text { IDEAS - Innovation } \\
\text { in the Department of } \\
\text { Education and Skills }\end{array}$ \\
\hline World Class Civil Service & $\begin{array}{l}\text { Office of the Revenue } \\
\text { Commissioners }\end{array}$ & PAYE Modernisation \\
\hline
\end{tabular}


Passport Office and the Office of the Revenue Commissioners, while decreasing for other departments such as the Department of Employment Affairs and Social Protection (DEASP);

- email interactions have increased significantly, becoming the number one interaction method for the first time, narrowly ahead of telephone interactions;

- customer satisfaction scores have improved for a second consecutive year; 89 per cent of customers stated their expectations were either met or exceeded;

- dissatisfaction stands at 20 per cent for 2019, a decline of seven points since 2017; the main reasons for dissatisfaction include slow processes, waiting time/automated system and being passed around;

- perceptions of the civil service have also increased, and new statements have received positive scores:

- 68 per cent of adults are confident that any personal data supplied to the civil service would be securely managed (59 per cent in 2017);

- 63 per cent of adults felt the civil service can be trusted to do what it says it will (new question);

- 57 per cent of adults stated it was simple and easy to interact with the civil service (new question).

Some new questions were introduced in 2019 focusing on awareness and use of online services. Eircode, which was introduced in 2015, was used 'always' or 'frequently' by 37 per cent, while 30 per cent stated they have never used their Eircode.

\section{Our Public Service 2020}

The first progress report for Our Public Service 2020, the current framework for public service reform and innovation, was published in August by DPER. The report outlines the implementation of key actions, including establishing governance structures, in the first year of the plan (Department of Public Expenditure and Reform, 2019b). Progress during this period was supported by a newly created Reform Evaluation Unit within DPER. The unit is working collaboratively with stakeholders to identify appropriate indicators to measure the successful implementation of actions in the framework, as well as to create stronger links between the reform programme and public expenditure processes. 
Details of the six headline actions that were prioritised are included in the progress report alongside case studies from across the public service (Department of Public Expenditure and Reform, 2019b). A major focus of Our Public Service 2020 is on developing a culture of innovation. The first ever public-service-wide Innovation Week took place from 9 to 13 December, an 'innovation culture network' has been established, funding has been provided for eighteen innovative pilot projects, ${ }^{1}$ and new accredited programmes in public service innovation have been established.

\section{Decentralisation}

Back in 2003, the then Minister for Finance announced the decentralisation of 10,300 civil and public servants from Dublin to 53 locations in 25 counties. This decentralisation programme was formally cancelled in 2011, in light of economic circumstances. At that stage around 3,400 civil servants had relocated to regional locations outside of Dublin. In the 2020 budget speech, however, Minister for Finance and Public Expenditure and Reform, Paschal Donohoe, TD, indicated that decentralisation is back on the table:

Demographic changes and the next wave of technological change will place new demands on our key offices and departments. The civil service of the future will be different in terms of its skills mix, use of technology and geographical footprint. We are therefore developing a longer-term vision and strategy for the civil service.

As part of this future strategy I have asked my officials to review future workforce and office requirements for our civil service and to report to me next year. This review will consider the location of support offices and services to ensure consistency with the goals of Ireland 2040 and balanced regional development. (Donohoe, 2019)

No formal plans have been published; however, the Minister of State with responsibility for the Office of Public Works indicated that this new phase of decentralisation will have a more targeted and focused approach, suggesting the development of civil service hubs in towns such as Athlone and Sligo (Doyle, 2019).

${ }^{1}$ See https://www.ops2020.gov.ie/networks/funding/ 


\section{Public Services Card}

The Public Services Card (PSC) received much media attention in 2019 following the outcome of an investigation by the Data Protection Commission (DPC). The card was launched in 2011 by the then Department of Social Protection as a method of identity verification for those accessing certain social welfare services and payments. There are currently approximately 3.2 million active users of the card. In 2013 the government indicated that the PSC would be the standard identity verification scheme to be used for access to all public services where appropriate. A number of services were identified for adoption of the PSC infrastructure. ${ }^{2}$ The PSC subsequently became a mandatory requirement for other services such as applying for a driver theory test, first-time applicants for a passport and citizenship applications. The relevant departments, however, have rolled back on this decision and the PSC is no longer required in these cases.

Following these and other developments on the use of the PSC, the DPC launched an investigation in 2017 regarding the legal basis of the card from a data protection perspective. Their final 172-page report was submitted in August and published by the DEASP, alongside a lengthy response, in September. The DPC's key findings are:

1. 'There is no lawful basis on which the DEASP can rely to SAFE 2-register ${ }^{3}$ and issue PSCs to persons required to obtain a PSC in order to transact with a public body other than the DEASP. While this report is addressed to the DEASP, as the relevant data controller, the corollary of this finding is that bodies other than the DEASP cannot insist that a person who does not already hold a PSC must obtain one.

2. The DEASP has not complied with the data retention principle, insofar that it keeps all of the supporting documentation it collects in the course of SAFE registration and issuing a PSC (for example, utility bills) for longer than is necessary.

3. The DEASP has not delivered sufficient transparency to the public in terms of what personal data it processes in the context of SAFE 2/PSC, for example, how that data is updated and shared with other public sector bodies for the purposes of decisionmaking.' (Data Protection Commission, 2019, p. 10).

2 https://www.welfare.ie/en/downloads/PSCFUTURE.pdf

${ }^{3}$ SAFE (Standard Authentication Framework Environment) is the process used by the DEASP to establish and verify a person's identity. SAFE2 is the level of authentication needed to issue a PSC. 
In terms of enforcement, the DPC ruled out the use of the card for any department or public body other than the DEASP. However, following their own consideration of the issue and advice from the Attorney General, the DEASP decided to continue to provide, and support the use of, the PSC not just by the DEASP but by the other public bodies that rely on it. In December the DPC served the DEASP with an official enforcement notice. The department has appealed the enforcement order and the appeal will be heard by the Circuit Court.

\section{Legislation}

In December the Cabinet approved the Official Languages (Amendment) Bill, 2019. Under this new legislation a non-mandatory target for recruitment of new civil servants with capacity to speak Irish will be set to one-fifth of new recruits. The bill provides for a national plan which will identify language gaps, harmonise standards between departments and agencies, and require public bodies to recognise the use of the síneadh fada and addresses in Irish.

\section{References}

Boyle, R. (2019). Public sector trends 2019 [State of the public service series, report no. 25]. Dublin: Institute of Public Administration.

Data Protection Commission. (2019). Final investigation report. An investigation by the Data Protection Commission in respect of the processing of personal data by the Department of Employment Affairs and Social Protection in relation to the public services card ("PSC") examining compliance with the obligations in relation to legal basis and transparency. Retrieved from http://www.welfare.ie/en/pdf/pr170919.pdf [20 January 2020].

Department of Public Expenditure and Reform. (2019a). Civil service renewal plan 2014. Progress report May 2019. Dublin: Department of Public Expenditure and Reform.

Department of Public Expenditure and Reform. (2019b). Our public service 2020. First progress report. Dublin: Department of Public Expenditure and Reform.

Donohoe, P. (2019). Budget 2020 speech. Retrieved from http://paschaldonohoe.ie/2019/10/budget-2020-speech/ [20 January 2020].

Doyle, K. (2019, September 24). New decentralisation plan to allow civil servants move out of the capital to regions. Irish Independent.

Government of Ireland. (2014). The civil service renewal plan. A vision and three year action plan for the civil service. Dublin: The Stationery Office. 
Public Appointments Service. (2019). 2018 annual report. Retrieved from https://publicjobs.ie/documents/2018_AnnualReport.pdf [20 January 2020].

Public Service Pay Commission. (2019). Report of the Public Service Pay Commission recruitment and retention module 2. Dublin: Public Service Pay Commission.

Top Level Appointments Committee. (2019). Seventh report to the Minister of Public Expenditure and Reform from the Top Level Appointments Committee (TLAC), 2018 developments \& trends. Dublin: Top Level Appointments Committee. 